CLINICAL STUDY

\title{
Serum glucose and insulin are associated with QTe and RR intervals in nondiabetic elderly
}

\author{
Charlotte van Noord $^{1,4}$, Miriam C J M Sturkenboom ${ }^{1,3}$, Sabine M J M Straus ${ }^{1,4}$, Albert Hofman ${ }^{1}$, Jan A Kors ${ }^{3}$, \\ Jacqueline C M Witteman ${ }^{1}$ and Bruno H Ch Stricker ${ }^{1,2,5}$ \\ Departments of ${ }^{1}$ Epidemiology, ${ }^{2}$ Internal Medicine and ${ }^{3}$ Medical Informatics, Erasmus Medical Center, Dr Molewaterplein 50, 3015 GE Rotterdam, \\ The Netherlands, ${ }^{4}$ The Dutch Medicines Evaluation Board, The Hague, The Netherlands and ${ }^{5}$ The Inspectorate for Health Care, The Hague, The Netherlands
}

(Correspondence should be addressed to B H Ch Stricker who is now at PO Box 2040, 3000 CA Rotterdam, The Netherlands;

Email: b.stricker@erasmusmc.nl)

\begin{abstract}
Aims: To study whether nondiabetic persons with impaired fasting serum glucose and hyperinsulinemia have QTc/QT interval prolongation and RR interval shortening in the electrocardiogram (ECG), and whether these were associated with an increased risk of sudden cardiac death.

Methods: This study consisted of two analyses. First, a cross-sectional analysis was used as part of the population-based Rotterdam Study including 1050 men and 1520 women ( $\geq 55$ years) without diabetes mellitus. Participants in round 3 of the Rotterdam Study for whom an ECG and fasting serum glucose and fasting insulin measurements were available were eligible for the study. Participants using digoxin or QTc-prolonging drugs and participants with left ventricular hypertrophy and left and right bundle branch block were excluded. The endpoints of the study were the lengths of the QTc, QT, and RR intervals. The associations were examined by means of linear regression analysis. Secondly, in all 6020 participants of the Rotterdam Study with an ECG, the associations between the QTc, QT, and RR intervals and sudden cardiac death were examined by means of Cox regression analysis.

Results: Overall, there was a significant association between impaired fasting serum glucose and the QTc interval with an increase of $2.6 \mathrm{~ms}$ (95\% confidence interval (CI): $0.3 ; 5.0)$ in those with fasting glucose $>6 \mathrm{mmol} / \mathrm{l}$. Hyperinsulinemia was also associated with QTc prolongation $(3.0 \mathrm{~ms}(0.8 ; 5.3))$ in those with fasting insulin $\geq 100 \mathrm{pmol} / \mathrm{l}$. Impaired fasting glucose (IFG) and hyperinsulinemia were significantly associated with a decrease of the RR interval $(-33.7 \mathrm{~ms}(-48.8 ;-18.6)$ and $-44.4 \mathrm{~ms}$ $(-58.7 ;-30.0)$ respectively). Participants in the fourth quartile of the QTc and QT intervals had a significantly increased risk of sudden cardiac death compared to participants in the first quartile (hazard ratio (HR) 2.87 (95\% CI: 2.02-4.06); HR 3.05 (1.99-4.67) respectively). Furthermore, there was a significant inverse association between the fourth quartile of the RR interval compared to the first quartile and the risk of sudden cardiac death (HR 0.49 (0.34-0.80)).

Conclusion: In this population-based study, we demonstrated that IFG and hyperinsulinemia are associated with a significantly increased QTc interval and with significant shortening of the RR interval, the latter probably due to an increased sympathetic activity. In addition, we demonstrated that both a prolonged QTc interval and a shortened RR interval are associated with an increased risk of sudden cardiac death.
\end{abstract}

European Journal of Endocrinology 162 241-248

\section{Introduction}

Diabetes mellitus is a common disease in the elderly which adversely affects cardiac repolarization, probably by autonomic imbalance. It is associated with prolongation of the heart-rate-corrected QT (QTc) interval which is the traditional measurement for assessing the duration of ventricular repolarization $(1,2)$. QTc prolongation may result in early afterdepolarizations, which in turn may induce re-entry and thereby provoke torsade de pointes and fatal ventricular arrhythmias (3-7).

In diabetes, hyperglycemia is a risk factor for cardiovascular disease. Nondiabetic participants with impaired fasting glucose (IFG) or hyperinsulinemia may have an increased risk of cardiovascular disease as well. Glucose intolerance and high fasting serum glucose levels and insulin levels have been associated with prolongation of the QTc interval in nondiabetic persons $(8,9)$. In a small study of 35 nondiabetic offspring of type 2 diabetic patients, it was demonstrated that during acute hyperinsulinemia, the QT interval remained unchanged, whereas the QTc interval increased (10). Serum glucose and hyperinsulinemia have been demonstrated to be associated with the RR interval in nondiabetic patients $(11,12)$. 
To our knowledge, no large studies on the association between serum glucose and insulin, and the uncorrected QT interval in nondiabetic persons have been published. Since diabetes mellitus has been associated with QTc and RR interval variation, and hyperglycemia is an independent risk factor for cardiovascular disease, our aim was to study whether nondiabetic participants with an IFG measurement and hyperinsulinemia have an increased risk of QTc prolongation and RR shortening and thereby an increased risk of sudden cardiac death. Therefore, we studied whether IFG and hyperinsulinemia are associated with the QTc, QT, and RR intervals in nondiabetic participants of a large prospective population-based study in elderly. Subsequently, we examined the association between the QTc, QT, and RR intervals and sudden cardiac death.

\section{Methods}

\section{Setting}

The Rotterdam Study is a prospective population-based cohort study, which started with a baseline visit between 1990 and 1993. The Medical Ethics Committee of the Erasmus Medical Center, Rotterdam, the Netherlands, approved the study. All inhabitants of Ommoord, a suburb of Rotterdam, aged 55 years and over were invited to participate $(n=10275)$. Of these, $7983(78 \%)$ gave their written informed consent and took part in the baseline examination. Objectives and methods of the Rotterdam Study have been described in detail elsewhere $(13,14)$. At baseline, all participants were visited at home for a standardized questionnaire, and 7151 were subsequently examined at the research center. Since the start of the study, follow-up visits took place in the period 1993 through 1996 for the second visit, in the period between 1997 and 1999 for the third visit, and in the period between 2002 and 2004 for the fourth visit. In addition to follow-up examinations, the cohort was continuously monitored for major morbidity and mortality through linkage with general practitioner and municipality records. Drug prescriptions dispensed to participants by automated pharmacies have been routinely stored in the database since January 1, 1991.

\section{Study designs}

We performed two analyses in the Rotterdam Study. First, we used a cross-sectional design to analyze the association between serum insulin and glucose, as assessed at the third visit to the research center, and QT, QTc, and RR intervals with data also from the third visit. Hereto, both the ECG and blood sampling were performed on the same day at the third visit to the research center. The reason was that during rounds 1 and 2 no data were available on both serum insulin and serum glucose. Secondly, for studying the association between QT, QTc, and RR intervals and sudden cardiac death, we used a prospective cohort design with the whole Rotterdam Study for whom an ECG was available. This analysis included the participants from the first analysis as described above. Since fasting glucose and fasting insulin measurements were only available at the third visit, we could not directly assess the effect between fasting glucose, fasting insulin, and sudden cardiac death due to the limited number of sudden cardiac death events occurring during follow-up since the third visit.

\section{Cross-sectional analysis of QT, QTc, and RR intervals}

All participants of the Rotterdam Study without diabetes mellitus who had an ECG and a fasting glucose and fasting insulin measurement at the third visit were enrolled in our first analysis. Diabetes mellitus (type I or II) was defined as the use of blood glucose-lowering medication and/or a nonfasting serum glucose level of $11.1 \mathrm{mmol} / \mathrm{l}$ or higher and/or fasting serum glucose levels $\geq 7 \mathrm{mmol} / \mathrm{l}$ at the third investigation or at any time prior to that moment (15). Digitally stored ECGs were available for 3818 participants at the time of the third visit. Missing ECGs were mainly due to temporary technical problems with ECG recordings.

We excluded participants with diabetes mellitus $(n=357)$, participants without a fasting glucose measurement $(n=168)$ or a fasting insulin measurement $(n=270)$ or insulin outliers $(n=1$ (insulin $=9292 \mathrm{pmol} / \mathrm{l})$ ), participants who were not fasting at blood sampling $(n=160)$, participants who used QTc-prolonging drugs as defined in list 1 of the website-based registry (www.azcert.org/ medical-pros/drug-lists/drug-lists.cfm) $(n=150)$, participants who used digoxin $(n=102)$, which is a QTc-shortening agent, and persons with a pacemaker $(n=13)$ as well as persons with evidence of left ventricular hypertrophy $(n=125)$ or left and right bundle branch block $(n=73$, $n=131$ ), since these conditions are associated with an altered QTc interval $(16,17)$. Overall, 2570 participants were included in this cross-sectional analysis.

\section{Cohort study of sudden cardiac death}

All cohort members of the Rotterdam Study with an ECG were enrolled in the study population. The study ended on one of the censoring dates (death or transferring out) or at the end of the study period (January 1, 2006). Overall, 6020 participants were included in the cohort analysis.

\section{QTe, QT, and RR intervals}

The endpoints of the study were the lengths of the QTc, QT, and RR intervals in ms. A 12-lead resting ECG was recorded with an ACTA electrocardiograph (ESAOTE, Florence, Italy) at a sampling frequency of $500 \mathrm{~Hz}$ and 
was stored digitally. All ECGs were processed by the Modular ECG Analysis System (MEANS) to obtain ECG measurements in agreement with the Food and Drug Administration (FDA) guidance for clinical evaluation of QT/QTc interval prolongation (www.emea.europa.eu/ pdfs/human/ich/000204en.pdf). The MEANS program has been evaluated and validated extensively (18-21). In one of these validation studies, ECGs with selected abnormalities were analyzed by 5 cardiologists and 11 different computer programs, of which MEANS performed as one of the best (21). MEANS determines common onsets and offsets for all 12 leads together on one representative averaged beat with the use of template matching techniques (19). The QT interval is determined from the start of the QRS complex until the end of the $T$ wave. To adjust for heart rate, Bazett's formula $(\mathrm{QTc}=\mathrm{QT} / \sqrt{\mathrm{RR}})$ was used (22). Additionally, the MEANS program determines left ventricular hypertrophy and left and right bundle branch block.

\section{Sudden cardiac death}

According to the most recent definition, sudden cardiac death is defined as i) a witnessed natural death attributable to cardiac causes, heralded by abrupt loss of consciousness, within 1 h of onset of acute symptoms, or ii) an unwitnessed, unexpected death of someone seen in a stable medical condition $<24 \mathrm{~h}$ previously with no evidence of a noncardiac cause $(23,24)$.

The ascertainment of sudden cardiac death cases has been described previously (7). In short, information on vital status is obtained from municipal health authorities in Rotterdam and GPs. Two research physicians independently coded all reported events, blinded to exposure, and judged the likelihood of sudden cardiac death according to the definition given above. In cases of disagreement, consensus was sought, and finally, a cardiologist reviewed all events. The index date was the date of death.

\section{Fasting glucose and insulin status}

At the third visit, fasting blood samples were drawn by venipuncture, and the serum glucose levels were measured using the glucose hexokinase method (Instruchemie) (25). Serum insulin was determined by metric assay (Biosource Diagnostics, Camarillo, CA, USA). This assay has no cross-reactivity with either proinsulin or C-peptide.

Subjects were classified into two categories according to glucose status: subjects with normal fasting glucose (NFG) and subjects with IFG. IFG is a recently defined diagnostic category based on fasting plasma glucose concentration (26). Analogous to the World Health Organization criteria of impaired glucose tolerance, it represents a metabolic stage intermediate between normal glucose homeostasis and diabetes mellitus and is associated with insulin resistance syndrome $(15,26)$. NFG was defined as a fasting glucose level below
$6.1 \mathrm{mmol} / \mathrm{l}$. IFG was defined as a fasting serum glucose level between 6.1 and $6.9 \mathrm{mmol} / \mathrm{l}(26)$.

Subjects were classified into two categories according to insulin status: subjects with normal insulin levels $(<100 \mathrm{pmol} / \mathrm{l})$ and subjects with hyperinsulinemia $(\geq 100 \mathrm{pmol} / \mathrm{l})$.

\section{Covariates}

Clinical measures were obtained during the visits at the Rotterdam Study research center. Hypertension was identified through the use of antihypertensive medication and/or through the assessment of blood pressure measurements according to the guidelines of the World Health Organization (27). Prevalence and incidence of myocardial infarction were assessed by hospital discharge diagnosis or in cases where a patient was not hospitalized, when signs and symptoms, analysis of the standard 12-lead ECG, and cardiac enzyme data were diagnostic of a myocardial infarction $(28,29)$. Prevalence and incidence of heart failure were assessed by the presence of suggestive signs and symptoms as described previously $(30,31)$. Hypercholesterolemia was defined as a total serum cholesterol level above $6.2 \mathrm{mmol} / \mathrm{l}$ or the use of cholesterol-lowering drugs, and hypertriglyceridemia was defined as a triglyceride level above $1.695 \mathrm{mmol} / \mathrm{l}$ (32).

\section{Statistical analysis}

The associations between the determinants, IFG and hyperinsulinemia, and the outcomes, QTc, QT, and RR intervals, were assessed through linear regression analysis. The relative risk of sudden cardiac death associated with the QTc, QT, and RR intervals was estimated by calculation of the hazard ratios (HR) using Cox proportional hazards models. All analyses were adjusted for age and gender. In addition, all covariates that were associated with the outcome $(P<0.10)$ were considered as potential confounders in both analyses. In the analyses assessing IFG and hyperinsulinemia, and the QTc, QT, and RR intervals, the following covariates were considered as potential confounders: body mass index (BMI), waist-to-hip ratio, hypercholesterolemia, hypertriglyceridemia, hypertension, myocardial infarction, heart failure, and use of $\beta$-blockers. In the analyses assessing the QTc, QT, and RR intervals and sudden cardiac death, the following covariates were considered as potential confounders: diabetes mellitus, hypercholesterolemia, hypertension, myocardial infarction, heart failure, BMI, use of QTc-prolonging drugs, use of $\beta$-blockers, and use of digoxin. The multivariate models were built to include all covariates that changed the association between exposure and the outcome by more than $5 \%$.

First, a linear regression analysis was conducted with the QTc, QT, and RR intervals as outcomes and with IFG and hyperinsulinemia and with fasting glucose and fasting insulin divided in quartiles as determinants. 
Table 1 Characteristics of study population

\begin{tabular}{|c|c|c|c|}
\hline & Total $(n=2570)$ & Impaired fasting glucose $(n=403)$ & Hyperinsulinemia $(n=455)$ \\
\hline Age (years, mean, s.D.) & $71.1(6.8)$ & $71.6(6.9)$ & $71.6(6.8)$ \\
\hline Gender (female) & $1520(59.1 \%)$ & $233(57.8 \%)$ & $290(63.7 \%)$ \\
\hline Mean QTc interval (ms) (s.D.) & $428.3(22.7)$ & $430.6(24.0)$ & $431.4(23.9)$ \\
\hline Mean QT interval (ms) (s.D.) & $406.8(29.7)$ & $403.8(31.9)$ & $402.4(29.3)$ \\
\hline Mean RR interval (ms) (s.D.) & $910.2(144.7)$ & $887.8(153.1)$ & $877.2(138.8)$ \\
\hline Body mass index $\left(\mathrm{kg} / \mathrm{m}^{2}\right)$ (mean, s.D.) & $26.0(3.4)$ & $27.3(3.6)$ & $28.2(3.6)$ \\
\hline Hypercholesterolemia ( $n, \%)$ & $220(8.6 \%)$ & $38(9.4 \%)$ & $40(8.8 \%)$ \\
\hline Hypertriglyceridemia ( $n, \%)$ & $671(26.1 \%)$ & $139(34.5 \%)$ & $210(46.2 \%)$ \\
\hline Hypertension ( $n, \%)$ & $776(30.2 \%)$ & $172(42.7 \%)$ & $188(41.3 \%)$ \\
\hline Myocardial infarction ( $n, \%)$ & $231(9.0 \%)$ & $35(8.7 \%)$ & $47(10.3 \%)$ \\
\hline Heart failure $(n, \%)$ & $64(2.5 \%)$ & $9(2.2 \%)$ & $19(4.2 \%)$ \\
\hline Use of $\beta$-blockers $(n, \%)$ & $374(14.6 \%)$ & $90(22.3 \%)$ & $89(19.6 \%)$ \\
\hline Mean fasting glucose (mmol/l) (s.D.) & $5.5(0.5)$ & $6.4(0.2)$ & $5.8(0.5)$ \\
\hline Mean fasting insulin (pmol/l) (s.D.) & 72.7 (41.9) & $97.9(52.6)$ & $141.3(46.5)$ \\
\hline
\end{tabular}

Bold indicates $P<0.05$.

Secondly, in participants with a NFG measurement, linear regression analysis was conducted with hyperinsulinemia as a determinant. Third, we performed a linear regression with both IFG and hyperinsulinemia as determinants. We performed sensitivity analyses by additionally adjusting for determinants of the metabolic syndrome: hypertension, hypertriglyceridemia, hypercholesterolemia, waist-to-hip ratio, and BMI. Fourth, we excluded all participants with both IFG and hyperinsulinemia.

Finally, a Cox regression was conducted with sudden cardiac death as outcome and the QTc, QT, and RR intervals divided in quartiles as determinants. In a sensitivity analysis, we excluded all confounders. The proportional hazards assumption was assessed using log-minus-log plots. All analyses were performed using SPSS for Windows version 15.0 (Chicago, IL, USA).

\section{Results}

\section{Subject characteristics}

The characteristics of the participants at the third visit are presented in Table 1. Overall, 2570 participants were included, of whom 1520 were females and 1050 were

Table 2 Association of fasting glucose and insulin with the QTc, QT, and RR intervals in nondiabetic participants.

\begin{tabular}{|c|c|c|c|c|}
\hline & $\begin{array}{l}\text { Number of } \\
\text { participants }\end{array}$ & $\begin{array}{l}\text { QTc prolongation } \\
\text { in } \mathrm{ms}(95 \% \mathrm{Cl})^{\mathrm{a}}\end{array}$ & $\begin{array}{l}\text { QT prolongation } \\
\text { in } \mathbf{m s}(95 \% \mathrm{Cl})^{\mathrm{b}}\end{array}$ & $\begin{array}{l}\text { RR prolongation } \\
\text { in } \mathbf{~} \mathbf{~}(95 \% \mathrm{Cl})^{\mathrm{a}}\end{array}$ \\
\hline $\begin{array}{l}\text { Fasting glucose } \\
\text { Normal fasting glucose }(\leq 6.0) \\
\text { Impaired fasting glucose }(6.1-6.9)\end{array}$ & $\begin{array}{l}2570 \\
2167 \\
403\end{array}$ & $\begin{array}{l}\text { Reference } \\
2.6(0.3 ; 5.0)\end{array}$ & $\begin{array}{l}\text { Reference } \\
0.0(-2.0 ; 2.1)\end{array}$ & $\begin{array}{l}\text { Reference } \\
-33.7(-48.8 ;-18.6)\end{array}$ \\
\hline $\begin{array}{l}\text { Quartiles } \\
1 \\
2 \\
3 \\
4 \\
P \text { value for linear trend }\end{array}$ & & $\begin{array}{l}\text { Reference } \\
-1.8(-4.0 ; 0.5) \\
1.0(-1.6 ; 3.5) \\
1.5(-0.9 ; 3.9) \\
0.073\end{array}$ & $\begin{array}{l}\text { Reference } \\
-1.9(-3.9 ; 0.0) \\
-0.7(-2.9 ; 1.5) \\
-1.6(-3.7 ; 0.4) \\
0.253\end{array}$ & $\begin{array}{l}\text { Reference } \\
0.1(-14.5 ; 14.7) \\
-15.7(-32.1 ; 0.7) \\
-36.2(-51.6 ;-20.8) \\
\mathbf{6 . 6} \times \mathbf{1 0}^{-\mathbf{7}}\end{array}$ \\
\hline $\begin{array}{l}\text { Fasting insulin } \\
\text { Normal insulin }(<100) \\
\text { Hyperinsulinemia }(\geq 100)\end{array}$ & $\begin{array}{l}2570 \\
2115 \\
455\end{array}$ & $\begin{array}{l}\text { Reference } \\
\mathbf{3 . 0}(\mathbf{0 . 8} ; \mathbf{5 . 3})\end{array}$ & $\begin{array}{l}\text { Reference } \\
-0.1(-2.0 ; 1.9)\end{array}$ & $\begin{array}{l}\text { Reference } \\
-44.4(-58.7 ;-30.0)\end{array}$ \\
\hline $\begin{array}{l}\text { Quartiles } \\
1 \\
2 \\
3 \\
4 \\
P \text { value for linear trend }\end{array}$ & & $\begin{array}{l}\text { Reference } \\
-1.3(-3.7 ; 1.1) \\
-0.5(-2.9 ; 2.0) \\
2.2(-0.3 ; 4.6) \\
0.067\end{array}$ & $\begin{array}{l}\text { Reference } \\
-1.8(-3.8 ; 0.3) \\
-2.0(-4.1 ; 0.1) \\
-1.7(-3.8 ; 0.4) \\
0.115\end{array}$ & $\begin{array}{l}\text { Reference } \\
-7.9(-23.1 ; 7.3) \\
-\mathbf{2 4 . 2}(-39.7 ;-8.7) \\
-\mathbf{5 4 . 8}(-\mathbf{7 0 . 3} ;-\mathbf{3 9 . 4}) \\
\mathbf{6 . 7} \times \mathbf{1 0}^{-13}\end{array}$ \\
\hline
\end{tabular}

$\mathrm{Cl}$, confidence interval. Glucose in mmol//; insulin in pmol/l. Quartiles: glucose (1) $\leq 5.0 \mathrm{mmol} / /$; (2) $5.1-5.5 \mathrm{mmol} / \mathrm{l}$; (3) $5.5-5.7$; (4) $\geq 5.8 \mathrm{mmol} / /$; insulin (1) $\leq 44 \mathrm{pmol} / \mathrm{l} ;$; (2) $45-64 \mathrm{pmol} / \mathrm{l}$; (3) $64-88 \mathrm{pmol} / \mathrm{l} ;$; 4 ) $\geq 89 \mathrm{pmol} / \mathrm{l}$.

Bold indicates $P<0.05$.

${ }^{a}$ Adjusted for age, gender, and hypertension.

${ }^{\mathrm{b}}$ Adjusted for age, gender, RR interval, and hypertension. 
Table 3 Association of insulin with the QTc, QT and RR interval in non-diabetic partcipants with a normal fasting glucose measurement.

\begin{tabular}{lllll}
\hline & $\begin{array}{l}\text { Number of } \\
\text { participants }\end{array}$ & $\begin{array}{l}\text { QTc prolongation } \\
\text { in ms }(95 \% \mathrm{CI})^{\mathrm{a}}\end{array}$ & $\begin{array}{l}\text { QT prolongation } \\
\text { in } \mathbf{~ m s ~}(95 \% \mathrm{Cl})^{\mathrm{b}}\end{array}$ & $\begin{array}{l}\text { RR prolongation } \\
\text { in } \mathbf{~ m s ~}(95 \% \mathrm{Cl})^{\mathrm{a}}\end{array}$ \\
\hline $\begin{array}{l}\text { Normal fasting glucose } \\
\begin{array}{l}\text { Fasting insulin } \\
\text { Normal insulin }(<100)\end{array}\end{array}$ & 2167 & & & \\
Hyperinsulinemia $(\geq 100)$ & 1855 & $\begin{array}{l}\text { Reference } \\
2.5(-0.2 ; 5.1)\end{array}$ & $\begin{array}{l}\text { Reference } \\
-1.5(-3.8 ; 0.7)\end{array}$ & $\begin{array}{l}\text { Reference } \\
-\mathbf{5 4 . 4}(-\mathbf{7 1 . 1} ;-\mathbf{3 7 . 7})\end{array}$ \\
\hline
\end{tabular}

$\mathrm{Cl}$, confidence interval. Insulin in pmol/l.

Bold indicates $P<0.05$

${ }^{a}$ Adjusted for age, gender, and hypertension.

${ }^{b}$ Adjusted for age, gender, RR interval, and hypertension.

males. The mean age of the study population was 71.1 years (s.D. 6.8 years). Mean fasting glucose was $5.5 \mathrm{mmol} / \mathrm{l}$ (s.D. $=0.5$ ), and mean fasting insulin was $72.7 \mathrm{pmol} / \mathrm{l}$ (s.D. $=41.9$ ). Overall, 403 participants had IFG and 455 participants had hyperinsulinemia.

\section{QTe, QT, and RR intervals}

The mean duration of the QTc interval was significantly shorter in males $(423.2 \mathrm{~ms})$ than in females (432.5 ms). Moreover, the mean duration of the RR interval was significantly longer in males (933.4 ms) than in females (895.7 ms).

Overall, there was a significant association between IFG and the QTc interval with an increase of $2.6 \mathrm{~ms}$ (95\% confidence interval (CI): $0.3 ; 5.0)$ after adjustment for age, gender, and hypertension (Table 2). Furthermore, hyperinsulinemia was also associated with QTc prolongation (3.0 ms (95\% CI: 0.8; 5.3)). However, IFG and hyperinsulinemia were not associated with an increase of the QT interval adjusted for age, gender, RR interval, and hypertension $(0.0 \mathrm{~ms}$ (95\% CI: $-2.0 ; 2.1)$ and -0.1 (95\% CI: - 2.0; 1.9) respectively).

IFG and hyperinsulinemia were associated with a significant decrease of the RR interval after adjustment for age, gender, and hypertension $(-33.7 \mathrm{~ms}$ (95\% CI: $-48.8 ;-18.6)$ and $-44.4 \mathrm{~ms}(95 \% \quad \mathrm{CI}:-58.7$; -30.0) respectively). Overall, there were 143 participants with both IFG and hyperinsulinemia. This combination was associated with a significant increase of the QTc interval $(5.0 \mathrm{~ms}(95 \%$ CI $1.3 ; 8.7))$ and a decrease of the RR interval ( $-28.1 \mathrm{~ms}(95 \% \mathrm{CI}-52.1$; $-4.1)$ ). After excluding these participants with both IFG and hyperinsulinemia, the overall results did not change substantially. After adjusting for hypertension, hypertriglyceridemia, hypercholesterolemia, waistto-hip ratio, and BMI, the results did not change substantially.

There was a nonsignificant trend toward a longer QTc interval in the highest quartiles of fasting glucose and fasting insulin (Table 2). In addition, there was a significant linear trend toward a shorter RR interval in the highest quartiles of fasting glucose and fasting insulin $(P<0.0001)$.

\section{NFG status}

In participants with NFG, hyperinsulinemia was not associated with the QTc or QT interval (Table 3). However, in subjects with NFG, hyperinsulinemia was significantly associated with a decrease of the RR interval after adjustment for age, gender, and hypertension $(-54.4 \mathrm{~ms}(95 \% \mathrm{CI}:-71.1 ;-37.7))$.

\section{QTe, QT, and RR intervals and sudden cardiac death}

The baseline characteristics of all participants are presented in Table 4. The mean age of the study population at baseline was 69.4 years, $59.6 \%$ was female. During the follow-up period, 209 persons were classified as definite sudden cardiac death and 54 as probable sudden cardiac death (Table 5). The proportional hazards assumption for a constant HR over time was met.

Participants in the fourth quartile of the QTc/QT interval had a significant increased risk of sudden cardiac death compared to participants in the first quartile (HR 2.87 (95\% CI: 2.02-4.06); HR 3.05 (95\% CI: 1.99-4.67) respectively). Furthermore, there was a significant inverse association between the fourth quartile of the RR interval compared to the first quartile and the risk of sudden cardiac death (HR 0.49 (95\% CI: 0.34-0.80)).

Table 4 Baseline characteristics of sudden cardiac death study population.

\begin{tabular}{lc}
\hline Characteristic & $\boldsymbol{n}=\mathbf{6 0 2 0}$ \\
\hline Mean age (years) (s.D.) & $69.4(9.2)$ \\
Gender (female) & $3585(59.6 \%)$ \\
Diabetes mellitus ( $n, \%)$ & $652(10.8 \%)$ \\
Hypercholesterolemia ( $n, \%)$ & $2539(42.2 \%)$ \\
Hypertension ( $n, \%)$ & $2025(33.6 \%)$ \\
Myocardial infarction ( $n, \%)$ & $715(11.9 \%)$ \\
Heart failure $(n, \%)$ & $203(3.4 \%)$ \\
Mean body mass index (kg/m $\left.{ }^{2}\right)$ (s.D.) & $29.3(15.1)$ \\
Use of QTc-prolonging drugs $(n, \%)$ & $348(5.8 \%)$ \\
Use of $\beta$-blockers ( $n, \%)$ & $1159(19.3 \%)$ \\
Use of digoxin $(n, \%)$ & $390(6.5 \%)$ \\
Mean QTc interval (ms) (s.D.) & $434.7(28.5)$ \\
Mean QT interval (ms) (s.D.) & $405.8(34.7)$ \\
Mean RR interval (ms) (s.D.) & $881.3(156.1)$ \\
\hline
\end{tabular}


Table 5 Association of QTc, QT, and RR intervals with sudden cardiac death.

\begin{tabular}{|c|c|c|c|c|}
\hline & Quartiles & $\operatorname{SCD}(n=263)$ & $\operatorname{HR}(95 \% \mathrm{Cl})^{\mathrm{a}}$ & HR $(95 \% \mathrm{Cl})^{\mathrm{b}}$ \\
\hline \multirow[t]{4}{*}{ QTc interval } & 1 & 51 & Reference & Reference \\
\hline & 2 & 59 & $1.39(0.95 ; 2.03)$ & $1.37(0.94-2.00)$ \\
\hline & 3 & 57 & $1.53(1.05-2.25)$ & $1.48(1.01-2.16)$ \\
\hline & 4 & 96 & $3.42(2.42 ; 4.84)$ & $2.87(2.02-4.06)$ \\
\hline \multirow[t]{4}{*}{ QT adjusted for RR interval } & 1 & 72 & Reference & Reference \\
\hline & 2 & 56 & $1.21(0.83-1.77)$ & $1.14(0.78-1.66)$ \\
\hline & 3 & 61 & $2.04(1.36-3.07)$ & $1.82(1.21-2.75)$ \\
\hline & 4 & 74 & $3.67(2.40-5.60)$ & $3.05(1.99-4.67)$ \\
\hline \multirow[t]{4}{*}{ RR interval } & 1 & 90 & Reference & Reference \\
\hline & 2 & 62 & $0.58(0.42-0.80)$ & $0.63(0.46-0.88)$ \\
\hline & 3 & 63 & $0.61(0.44-0.84)$ & $0.68(0.49-0.94)$ \\
\hline & 4 & 48 & $0.46(0.32-0.66)$ & $0.49(0.34-0.80)$ \\
\hline
\end{tabular}

SCD, sudden cardiac death; HR, hazard ratio. Quartiles: QTc (1) $\leq 416 \mathrm{~ms}$; (2) 417-431 ms; (3) 432-449; (4) $\geq 450 \mathrm{~ms}$; QT (1) $\leq 382 \mathrm{~ms}$; (2) $383-403 \mathrm{~ms}$; (3) 404-425 ms; (4) $\geq 426$ ms; RR (1) $\leq 770 \mathrm{~ms}$; (2) 771-869 ms; (3) 870-979 ms; (4) $\geq 940 \mathrm{~ms}$.

Bold indicates $P<0.05$.

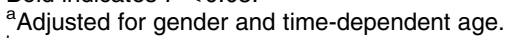

${ }^{b}$ QTc interval additionally adjusted for time-dependent myocardial infarction and use of QTc-prolonging drugs and digoxin; QT interval additionally adjusted for time-dependent myocardial infarction and use of QTc-prolonging drugs; RR interval additionally adjusted for use of $\beta$-blockers and digoxin.

In a sensitivity analysis, we excluded all confounders instead of adjusting for these potential confounders. An increased QTc/QT interval and a decreased RR interval were still significantly associated with an increased risk of sudden cardiac death. However, due to the lower numbers of sudden cardiac death cases after these exclusions, the estimates were somewhat lower. Participants in the fourth quartile of the QTc/QT interval had a significantly increased risk of sudden cardiac death compared to participants in the first quartile (HR 2.12 (95\% CI: 1.36-3.32); HR 2.65 (95\% CI: 1.54-4.56) respectively). Furthermore, there was a significant inverse association between the fourth quartile of the RR interval compared to the first quartile and the risk of sudden cardiac death (HR 0.63 (95\% CI: 0.40-0.98)).

\section{Discussion}

In this population-based study, we demonstrated that nondiabetic participants with IFG and hyperinsulinemia had a significantly increased QTc interval and a significantly shorter RR interval than participants with NFG and insulin measurements. Fasting glucose and fasting insulin were not associated with the QT interval after adjustment for the RR interval. Furthermore, we demonstrated that an increased QTc/QT interval and a decreased RR interval are associated with a significantly increased risk of sudden cardiac death. Although a QTc interval prolongation of $2-3 \mathrm{~ms}$ in one individual usually remains without clinical consequences, an average shift of 2-3 ms in a Gaussian distribution on a population level will inevitably push more individuals into the upper percentiles of the QTc interval with its increased risk of ventricular arrhythmias and sudden cardiac death.

Our findings suggest that the association of glucose and insulin with the QTc interval is due to the underlying shortening of the RR interval, since QTc is calculated by Bazett's formula using the square root of the RR interval in the denominator. However, we confirmed that both an increased QTc interval and a shortened RR interval are associated with an increased risk of sudden cardiac death, as has been demonstrated before $(7,33-35)$. Our findings cannot be explained by the metabolic syndrome, since additional adjustment for the determinants of the metabolic syndrome did not change the results substantially. We demonstrated that the association of hyperinsulinemia with the RR interval was even more pronounced in participants with NFG. This suggests that in subjects with nonsymptomatic insulin resistance syndrome, increased sympathetic nervous system activity and autonomic imbalance occur.

IFG and hyperinsulinemia have been associated with the QTc interval in nondiabetic persons $(8,9)$. However, a relation with the QT interval has only been demonstrated in a small study of 35 nondiabetic offspring of type 2 diabetic patients (10). That study showed that during acute hyperinsulinemia, the QT interval remained unchanged, whereas the QTc interval increased. IFG and hyperinsulinemia have been demonstrated to be associated with the RR interval in nondiabetic patients $(11,12)$. Several mechanisms by which IFG and hyperinsulinemia may affect the QTc and RR intervals have been reported, among others are increased sympathetic activity, autonomic imbalance, impairment of the hERG channel, raised production of free radicals, disturbed myocardial membrane function, and a reduction of $\mathrm{Na}^{+} / \mathrm{K}^{+}$-ATPase activity (36-38). Although the exact underlying mechanism may be unknown, increased sympathetic activity caused by hyperinsulinemia may decrease the RR interval (39). Furthermore, the insulin resistance syndrome can be considered as a pre-stage of diabetes mellitus, which suggests the early presence of autonomic nervous dysfunction (40). 
Our study has several strengths. An advantage of the Rotterdam Study is its population-based character. Although we limited our study population, selection bias is unlikely because the characteristics of the study population were comparable to the baseline characteristics of the whole population of the Rotterdam Study. Furthermore, information bias is unlikely because data were gathered prospectively and because of the use of digital ECG recordings. The digital ECGs were all automatically interpreted using the MEANS system which reduced intra- and interobserver variability in the assessment of the QTc, QT, and RR intervals. Confounding was minimized by adjusting for all known risk factors. However, our study also has some limitations. Since fasting glucose and fasting insulin measurements were only available at the third visit, we could not directly assess the effect between fasting glucose, fasting insulin, and sudden cardiac death due to the limited number of sudden cardiac death events occurring during follow-up since the third visit. Therefore, for studying the association between QT, QTc, and RR intervals and sudden cardiac death, we used a prospective cohort design with the whole Rotterdam Study for whom an ECG was available. This analysis included the participants from the first analysis. Because of the cross-sectional design we cannot exclude that RR interval shortening was already present in some patients before the increase of glucose and insulin. Therefore, the results from this study should be confirmed with longitudinal data from other large cohorts. Finally, our study population consisted of participants aged 55 years and older. Whether our findings can be generalized to other age groups requires further study. In addition, since thyroid hormones were available in only a minority of the study population, we could not assess the effect of thyroid dysfunction on our results. However, we do not expect that thyroid hormones would be a strong confounder, since we have shown previously that (sub) clinical hyperthyroidism was not associated with diabetes mellitus in the Rotterdam Study (41).

In conclusion, we demonstrated in this populationbased study that IFG and hyperinsulinemia are significantly associated with an increased QTc interval but not with an increase of the QT interval. This is explained by a shortening of the RR interval, probably due to an increased sympathetic activity. We demonstrated that both an increased QTc/QT interval and a shortened RR interval are associated with an increased risk of sudden cardiac death.

\section{Declaration of interest}

The authors declare that there is no conflict of interest that could be perceived as prejudicing the impartiality of the research reported.

\section{Funding}

This research did not receive any specific grant from any funding agency in the public, commercial, or not-for-profit sector.

\section{References}

1 Brown DW, Giles WH, Greenlund KJ, Valdez R \& Croft JB. Impaired fasting glucose, diabetes mellitus, and cardiovascular disease risk factors are associated with prolonged QTc duration. Results from the Third National Health and Nutrition Examination Survey. Journal of Cardiovascular Risk 20018 227-233.

2 Solini A, Passaro A, D’Elia K, Calzoni F, Alberti L \& Fellin R. The relationship of plasma glucose and electrocardiographic parameters in elderly women with different degrees of glucose tolerance. Aging 200012 249-255.

3 Lasser KE, Allen PD, Woolhandler SJ, Himmelstein DU, Wolfe SM \& Bor DH. Timing of new black box warnings and withdrawals for prescription medications. Journal of the American Medical Association $20022872215-2220$.

4 Roden DM. Drug-induced prolongation of the QT interval. New England Journal of Medicine $20043 \mathbf{5 0} 1013-1022$.

5 Al-Khatib SM, LaPointe NM, Kramer JM \& Califf RM. What clinicians should know about the QT interval. Journal of the American Medical Association 2003289 2120-2127.

6 Yap YG \& Camm AJ. Drug induced QT prolongation and torsades de pointes. Heart $2003 \mathbf{8 9} 1363-1372$.

7 Straus SM, Kors JA, De Bruin ML, van der Hooft CS, Hofman A, Heeringa J, Deckers JW, Kingma JH, Sturkenboom MC, Stricker BH \& Witteman JC. Prolonged QTc interval and risk of sudden cardiac death in a population of older adults. Journal of the American College of Cardiology 200647 362-367.

8 Dekker JM, Feskens EJ, Schouten EG, Klootwijk P, Pool J \& Kromhout D. QTc duration is associated with levels of insulin and glucose intolerance. The Zutphen Elderly Study. Diabetes 199645 376-380.

9 Lefrandt JD, Diercks GF, van Boven AJ, Crijns HJ, van Gilst WH \& Gans RO. High fasting glucose and QTc duration in a large healthy cohort. Diabetologia 200043 1332-1333.

10 Laitinen T, Vauhkonen I, Niskanen L, Hartikainen J, Uusitupa M \& Laakso M. Prolonged corrected QT interval is associated with acute and chronic hyperinsulinemia in nondiabetic subjects. Diabetes Care 200326 2480-2481.

11 Schroeder EB, Chambless LE, Liao D, Prineas RJ, Evans GW, Rosamond WD \& Heiss G. Atherosclerosis risk in communities: diabetes, glucose, insulin, and heart rate variability: the Atherosclerosis Risk in Communities (ARIC) study. Diabetes Care 200528 668-674.

12 Festa A, D’Agostino R Jr, Hales CN, Mykkanen L \& Haffner SM. Heart rate in relation to insulin sensitivity and insulin secretion in nondiabetic subjects. Diabetes Care 200023 624-628.

13 Hofman A, Grobbee DE, de Jong PT \& van den Ouweland FA. Determinants of disease and disability in the elderly: the Rotterdam Elderly Study. European Journal of Epidemiology 1991 7 403-422.

14 Hofman A, Breteler MM, van Duijn CM, Krestin GP, Pols HA, Stricker BH, Tiemeier H, Uitterlinden AG, Vingerling JR \& Witteman JC. The Rotterdam Study: objectives and design update. European Journal of Epidemiology 200722 819-829.

15 WHO: Diabetes Mellitus. Technical Reports Series 894. Geneva, World Health Organisation, 1985.

16 Kulan K, Ural D, Komsuoglu B, Agacdiken A, Goldeli O \& Komsuoglu SS. Significance of QTc prolongation on ventricular arrhythmias in patients with left ventricular hypertrophy secondary to essential hypertension. International Journal of Cardiology 199864 179-184.

17 Piotrowicz K, Zareba W, McNitt S \& Moss AJ. Repolarization duration in patients with conduction disturbances after myocardial infarction. American Journal of Cardiology 200799 $163-168$.

18 de Bruyne MC, Kors JA, Hoes AW, Kruijssen DA, Deckers JW, Grosfeld M, van Herpen G, Grobbee DE \& van Bemmel JH. Diagnostic interpretation of electrocardiograms in populationbased research: computer program research physicians, or cardiologists? Journal of Clinical Epidemiology $1997 \mathbf{5 0} 947-952$. 
19 van Bemmel JH, Kors JA \& van Herpen G. Methodology of the modular ECG analysis system MEANS. Methods of Information in Medicine 199029 346-353.

20 Willems JL, Abreu-Lima C, Arnaud P, van Bemmel JH, Brohet C, Degani R, Denis B, Gehring J, Graham I, van Herpen G, Machado H, Macfarlane PW, Michaelis J, Moulopolis S, Rubel P \& Zywietz C. The diagnostic performance of computer programs for the interpretation of electrocardiograms. New England Journal of Medicine 1991325 1767-1773.

21 Willems JL, Arnaud P, van Bemmel JH, Bourdillon PJ, Degani R, Denis B, Graham I, Harms FM, Macfarlane PW, Mazzocca G, Meyer J \& Zywietz C. A reference data base for multilead electrocardiographic computer measurement programs. Journal of the American College of Cardiology 198710 1313-1321.

22 Bazett HC. The time relations of the blood-pressure changes after excision of the adrenal glands, with some observations on blood volume changes. Journal of Physiology 192053 320-339.

23 Myerburg RJ \& Castellanos A. Language and interpretation of clinical trial outcomes: alternates, surrogates, and composites. Heart Rhythm 20041 538-539.

24 Priori SG, Aliot E, Blomstrom-Lundqvist C, Bossaert L, Breithardt G, Brugada P, Camm AJ, Cappato R, Cobbe SM, Di Mario C, Maron BJ, McKenna WJ, Pedersen AK, Ravens U, Schwartz PJ, Trusz-Gluza M, Vardas P, Wellens HJ \& Zipes DP. Task force on sudden cardiac death of the European Society of Cardiology. European Heart Journal 200122 1374-1450.

25 Neeley WE. Simple automated determination of serum or plasma glucose by a hexokinase-glucose-6-phosphate dehydrogenase method. Clinical Chemistry 197218 509-515.

26 The Expert Committee on the Diagnosis and Classification of Diabetes. Report of the Expert Committee on the Diagnosis and Classification of Diabetes Mellitus. Diabetes Care 199720 1183-1197.

27 WHO: World Health Organization-International Society of Hypertension Guidelines for the Management of Hypertension. Guidelines Subcommittee. Journal of Hypertension 199917 151-183.

28 Bots ML, Hoes AW, Koudstaal PJ, Hofman A \& Grobbee DE. Common carotid intima-media thickness and risk of stroke and myocardial infarction: the Rotterdam Study. Circulation 199796 1432-1437.

29 Vliegenthart R, Oudkerk M, Song B, van der Kuip DA, Hofman A \& Witteman JC. Coronary calcification detected by electron-beam computed tomography and myocardial infarction. The Rotterdam Coronary Calcification Study. European Heart Journal 200223 1596-1603.

30 Bleumink GS, Knetsch AM, Sturkenboom MC, Straus SM, Hofman A, Deckers JW, Witteman JC \& Stricker BH. Quantifying the heart failure epidemic: prevalence, incidence rate, lifetime risk and prognosis of heart failure. The Rotterdam Study. European Heart Journal 200425 1614-1619.

31 Mosterd A, Hoes AW, de Bruyne MC, Deckers JW, Linker DT, Hofman A \& Grobbee DE. Prevalence of heart failure and left ventricular dysfunction in the general population; The Rotterdam Study. European Heart Journal 199920 447-455.

32 Expert Panel on Detection EaToHBCiA. Executive summary of The third report of The National Cholesterol Education Program (NCEP) expert panel on detection, evaluation, and treatment of high blood cholesterol in adults (Adult Treatment Panel III). Journal of the American Medical Association $20012852486-2497$.

33 Jouven X, Empana JP, Schwartz PJ, Desnos M, Courbon D \& Ducimetiere P. Heart-rate profile during exercise as a predictor of sudden death. New England Journal of Medicine 2005352 1951-1958.

34 Shaper AG, Wannamethee G, Macfarlane PW \& Walker M. Heart rate, ischaemic heart disease, and sudden cardiac death in middleaged British men. British Heart Journal 1993 70 49-55.

35 Kannel WB, Kannel C, Paffenbarger RS Jr \& Cupples LA. Heart rate and cardiovascular mortality: the Framingham Study. American Heart Journal 1987113 1489-1494.

36 Marfella R, Rossi F \& Giugliano D. Hyperglycemia and QT interval: time for re-evaluation. Diabetes, Nutrition $\mathcal{E}$ Metabolism 200114 63-65.

37 Zhang Y, Han H, Wang J, Wang H, Yang B \& Wang Z. Impairment of human ether-a-go-go-related gene (HERG) $\mathrm{K}^{+}$channel function by hypoglycemia and hyperglycemia, Similar phenotypes but different mechanisms. Journal of Biological Chemistry $2003 \mathbf{2 7 8}$ 10417-10426.

38 Ben-David J \& Zipes DP. Differential response to right and left ansae subclaviae stimulation of early after depolarizations and ventricular tachycardia induced by cesium in dogs. Circulation $1988 \mathbf{7 8}$ 1241-1250.

39 Anderson EA, Hoffman RP, Balon TW, Sinkey CA \& Mark AL. Hyperinsulinemia produces both sympathetic neural activation and vasodilation in normal humans. Journal of Clinical Investigation $1991872246-2252$.

40 Oka H, Mochio S, Sato K, Sato H \& Katayama K. Prolongation of QTc interval and autonomic nervous dysfunction in diabetic patients. Diabetes Research and Clinical Practice 199631 63-70.

41 van Noord C, van der Deure W, Sturkenboom M, Straus S, Hofman A, Visser T, Kors J, Witteman J \& Stricker B. High free $\mathrm{T}_{4}$ levels are associated with QTc prolongation in males. Journal of Endocrinology 2008198 253-260.

Received 23 October 2009

Accepted 5 November 2009 